\title{
Hidden association between Schistosoma mansoni and Ascaris lumbricoides infections
}

\author{
Associações escondidas entre infecções por Schistosoma mansoni e Ascaris lumbricóides
}

\author{
Munir Chamone ${ }^{1}$; Elza Erichsen²; Gregorio Saraiva Atuncar ${ }^{3}$; Alan Lane de Melo ${ }^{4}$ \\ ${ }^{1}$ Professor Adjunto aposentado, Departamento de Bioquímica-Imunologia, Instituto de Ciências Biológicas \\ Universidade Federal de Minas Gerais, Belo Horizonte, MG, Brasil; ${ }^{2}$ Professora Associada, Departamento de \\ Propedêutica Complementar, Faculdade de Medicina, Universidade Federal de Minas Gerais, Belo Horizonte, MG, \\ Brasil. ${ }^{3}$ Professor Associado, Departamento de Estatística, Instituto de Ciências Exatas, Universidade Federal de \\ Minas Gerais, Belo Horizonte, MG, Brasil; ${ }^{4}$ Professor Associado, Departamento de Parasitologia, Instituto de \\ Ciências Biológicas, Universidade Federal de Minas Gerais, Belo Horizonte, MG, Brasil.
}

\begin{abstract}
The parasitism by Ascaris lumbricoides tends to affect the course of human infection with Schistosoma mansoni on several levels. At least two aspects were addressed in this communication: (1) the influence of the immune response with complementactivating antibody functions (cytotoxic antibody against schistosomula) and (2) the interference between these species of helminths indicated by analyses carried out after the rearrangement of data from seven prevalence surveys from the literature to illustrate our purpose. In fact, the approach focusing on these seven authors' contributions has not been previously submitted considering the associations between $\mathrm{S}$. mansoni and $\mathrm{A}$. lumbricoides infections. Present findings suggest that the occurrence of $A$. lumbricoides infection affects both the development of cytotoxic antibodies against schistosomula and the prevalence of $\mathrm{S}$. mansoni infection that features a negative association. Key Words:Schistosoma mansoni. Ascaris lumbricoides. Cytotoxic antibody. Prevalence.

Resumo

O parasitismo por Ascaris lumbricoides tende a afetar o curso da infecção humana pelo Schistosoma mansoni em vários níveis. No presente estudo procurou-se abordar dois destes aspectos: (1) a influência da resposta imune mediada por anticorpos (anticorpos citotóxicos contra esquistossômulos) e (2) a interferência entre estas espécies de helmintos indicada por análises realizadas após o rearranjo de dados de sete estudos de prevalência encontrados na literatura pertinente para ilustrar o nosso propósito. De fato, a abordagem centrada nas contribuições destes sete autores não foi previamente submetida considerando as associações entre infecções por S. mansoni e A. lumbricoides. Os resultados apresentados sugerem que a ocorrência de infecção por A. lumbricoides afeta o desenvolvimento de anticorpos citotóxicos contra esquistossômulos e a prevalência de infecção por S. mansoni que caracteriza uma associação negativa.

Palavras-chave: Schistosoma mansoni. Ascaris lumbricoides. Anticorpo citotóxico. Prevalência
\end{abstract}

\section{INTRODUCTION}

The co-existence of Schistosoma mansoni and hookworm helminths in human beings has been investigated ${ }^{1-6}$. These concomitant infections raise the possibility that one species may influence the transmission pattern or disease features of the other. Moreover, there is accumulating evidence that human hookworm infection concurrent with S. mansoni is functionally promiscuous at least at three levels of considerable importance: physiological and immunological ${ }^{7-9}$ and parasitological ${ }^{10-12}$. So far, only a few studies on the association between Ascaris lumbricoides and $S$. mansoni infections in humans beings have been reported $4,7,13,14,15$. These studies are restricted to skin anaphylactic antibody effector functions, to complement-fixing anti-adult worm antibodies for

Recebido em 29 de julho de 2011; revisado em 26 de agosto de 2011. Correspondência / Correspondence:Alan Lane de Melo. Av. Antonio Carlos 6627, CEP 30.270-901 Belo Horizonte, MG, Brasil. E-mail: aldemelo@icb.ufmg.br serological diagnosis of schistosomiasis ${ }^{16}$, intensity of $S$. mansoni infections and the correlation between $S$. mansoni infection and altered immune responses to $A$. lumbricoides and hookworm. Here, we extend this investigation to examine a possible association of $S$. mansoni and $A$. lumbricoides. Titers of cytotoxic antibody admittedly related to antibody-complement-mediated schistosomula killing were examined in individuals concomitantly harbouring $S$. mansoni and $A$. lumbricoides, and it was also investigated whether the prevalence of Ascaris remained the same while the prevalence of S. mansoni infection increased.

\section{MATERIAL AND METHODS Population}

A total of 34 individuals passing S. mansoni eggs in the stools, as detected by the sedimentation method (taking into consideration the presence of geohelminths), was randomly selected from a public ambulatory clinic 
at metropolitan region of Belo Horizonte, Minas Gerais, with permission of the state health Agency (Secretaria Estadual de Saúde de Minas Gerais). In addition, prior the enrolment in the study, informed consent was obtained for all adult volunteers or parent/guardian of each child selected for the study according to official regulations. These individuals received a single oral dose of Oxamniquine $(15 \mathrm{mg} / \mathrm{kg})$ and/or mebendazole (100 mg twice a day for 3 consecutive days) according to parasite identified in parasitological test. The schistosome infected subjects were followed up monthly after treatment, but only 14 were followed until the end of the serological investigations. They were aged 9-48 years (mean 24.4). Two groups were assembled depending to either the presence or absence of eggs of Ascaris lumbricoides in faeces.

\section{Evaluation of cytotoxic antibody titre}

To determine the cytotoxic antibody titre, serial two-fold dilutions of the serum were prepared. Samples were tested in duplicate and the results were averaged. It is noteworthy that previous results on cytotoxicity assay of antibody against $S$. mansoni schistosomula were already presented in Master's dissertation of Erichsen ${ }^{17}$. For the serum lethal antibody assays, blood samples were taken from subjects above mentioned that return to be re-examined. It was demonstrated that the titration to an end point of $50 \%$ dead schistosomula had an advantage over conventional titration. Briefly, 200-250 fresh schistosomula in $100 \mu \mathrm{L}$ NCTC-135 medium were treated for $30 \mathrm{~min}$ at $37^{\circ} \mathrm{C}$ with $100 \mu \mathrm{L}$ of an appropriate dilution of heat-inactivated sera (first dilution $=1: 4$ ) obtained from individuals with chronic S. mansoni infection. After these manipulations, the organisms were washed and resuspended in $240 \mu \mathrm{L}$ of solution, and $10 \mu \mathrm{L}$ of a 1:2 dilution of pooled guinea pig serum (complement source) were added to each tube. The mixture was incubated at $37^{\circ} \mathrm{C}$ for $16-18 \mathrm{~h}$ in a $5 \%$ $\mathrm{CO}_{2}$ humid atmosphere. The control consisted of heatinactivated $\left(56^{\circ} \mathrm{C}, 30 \mathrm{~min}\right)$ complement source, a mixture in which schistosomula had been treated with heated normal sera or schistosomula coated with antibodies and incubating them in NCTC-135 medium only. The percentage of dead schistosomula in the control mixture was less than $15 \%$. To determine the cytotoxic antibody titre, serial two-fold dilutions of the serum were prepared. Samples were tested in duplicate and the results were averaged. Thus, in the present study, instead of the conventional titration, a titration to an end point of $50 \%$ dead schistosomula was used, and the end point is where the titration ends in practice. The aim of this titration is to measure the antibody cytotoxicity in serum and to express this as a titre. In fact, a graph (not shown) has already been made by plotting the serum dilution along the horizontal axis and the percent dead schistosomula along the vertical axis. This procedure produced a sigmoid curve and, from the point at which the curve intercepted the 50 percent level of dead schistosomula, a line was dropped to the horizontal axis. This method gave the 50 percent end point in terms of serum dilution and became possible to compare results of different titrations.

\section{Search on publications concerning the co-infection with S. mansoni and A. lumbricoides at epidemiologic level}

A bibliographic survey was conducted by means of investigation in several online databases. From 170 published prevalence surveys undertaken among populations in Brazil, Yemen and Africa, only 7 out of 170 publications ${ }^{10,18,19,20,21,22,23}$ which considered different ecological settings and socio-cultural patterns, all age groups and gender were elected for the present analysis. The rearrangement of the data contained in the selected papers (excepted Hiatt's study ${ }^{22}$ ) enabled the preparation of tables that show in three different ways the link between the prevalences of $S$. mansoni and $A$. lumbricoides. No S. haematobium infection was detected in the communities considered.

\section{Statistical analysis}

The sign of differences of the cytotoxic antibody titre is designed so that plus (+) and minus (-) signs in after-before studies are used to denote change in magnitude, to indicate "gain" or "loss" because changes were seen in either direction.

An arithmetic mean was used for separating higher half number of a prevalence of $S$. mansoni distribution, from the lower half, where the mean of a list of numbers could be found by arranging all observations from lowest to highest value with respect to one variable (S. mansoni) and picking the middle one. Afterward, corresponding values of other variables (Ascaris) were recorded and compared. Ordered prevalences of $S$. mansoni infections are presented with the corresponding prevalences of $A$. lumbricoides infection. From these sequences, it was determined if the number of Ascaris cases did or did not remain the same while the prevalence of $S$. mansoni infection progressed. Also, rank transformation of original data (prevalence of $A$. lumbricoides and S. mansoni infections) for analysis was applied because exact numerical measurements are not available. When consider forming pairs of observations a pair of observations is concordant if the subject who is higher on one variable also is higher on the other variable. Otherwise a pair of observations is discordant if the subject who is higher on one variable is lower on the other variable. When a Table is used combining two types of association (negative/positive), concordant/discordant methods provide alternative methods for assessing the strength of the tendency of two variables, namely S. mansoni and Ascaris, to move in the same (opposite) direction. The concordance (negative association) and discordance 
(positive association) measures this tendency in a direct way. Recall that any of the chosen method not measure strength of relationship.

\section{RESULTS}

First, titters of complement-dependent cytotoxic antibodies against $S$. mansoni schistosomula were investigated. The changes in cytotoxic antibody before or ${ }^{3} 5$ months after treatment with anti-schistosomal and/or anti-geohelminth drugs are shown in Table 1. Eggs of $S$. mansoni were found after treatment in only two individuals and of A. lumbricoides, Strongyloides stercoralis, Trichuris trichiura and Hymenolepis nana in one case each, and cysts of Entamoeba coli were found in 2 cases and of Giardia duodenalis in 1 case).

Herein, in the presence of $A$. lumbricoides, the gain of antibody activity was more frequent after treatment for S. mansoni because 6 out of 7 cases showed increased gain in antibody activity when there was co-infection with A. lumbricoides, while only 1 out of 7 cases showed increased gain in activity in the absence of this nematode. However, looking at the geometric mean antibody activity titre, before group A drug regime in which A. lumbricoides is absent, there was a higher cytotoxic antibody titre in comparison to those infected with S. mansoni plus A. Iumbricoides or group B ( $92.8 \mathrm{vs}$ 59.1). The titre of the serum cytotoxicity was affected by the presence of $A$. lumbricoides.

The investigation to examine a possible association between S. mansoni and Ascaris was extended to epidemiological view point from laboratory findings. Then, we intend to evaluate if changes in prevalence of S. mansoni infection tend to be influenced by co-infection with $A$. lumbricoides. To assess the prevalence investigations, we present seven data sets from the literature to illustrate our purpose

Hiatt ${ }^{22}$ had recorded in his Table 3 that while Twawuzgi, an Ethiopian village, had a prevalence of $43.3 \%$ for S. mansoni and $35.4 \%$ for A. lumbricoides cases, Gurumba village had a low prevalence $(14 \%)$ of blood flukes but an increased proportion of roundworms of $84.7 \%$. In short, in this location, the highest prevalence of $A$. lumbricoides infection is seen associated with the lowest prevalence of $S$. mansoni infection. These results are corroborated by Chunge and co-works ${ }^{21}$ who reported that while the Miu community (Kenya) had an estimated lower prevalence of schistosomiasis mansoni compared to the Kitinger community ( $21.6 \%$ vs $26.2 \%)$, the prevalence of $A$. lumbricoides was in the opposite direction ( $2.5 \%$ vs $1.1 \%)$.

These results are corroborated by six examples that contain rearrangement of published material to investigate if the prevalence of $A$. lumbricoides remained the same while the prevalence of schistosomiasis progressed.
Alemayehu and colleagues ${ }^{18}$ data were collected from inhabitants of 28 microdam regions in Ethiopia (Table 2) with at least one case of blood flukes or $A$. lumbricoides infections $(n=1429)$. The arithmetic mean of $A$. lumbricoides infection in the first half of the ordered sequence of S. mansoni values is 4.3 (Table 2a) and in the second it is lower or 2.3 (Table 2b). It is suggested that proportions of $A$. lumbricoides infections decreased while the prevalence of $S$. mansoni progressed. It should be noted that the number 31 (Table 2a) may be an outlier in the data of prevalence of $A$. lumbricoides, and that can affect the magnitude of the difference. However, once more, there is some evidence of a negative association between prevalence of $S$. mansoni and $A$. lumbricoides infections.

Furthermore, age was taken into consideration to investigate this possible negative association between species of helminths in Americaninhas ( $17^{\circ} 8^{\prime} \mathrm{S}, 41^{\circ} 12^{\prime}$ W), a Brazilian rural area in Minas Gerais, it was verified after rearranging data from Fleming and colleagues ${ }^{10}$ and using ranks transformation of original data (Table 3) that the rank sum (for prevalence) in S. mansoni infection cases at left of the middle sequence of age group was 16, and in A. lumbricoides cases it was 30 . At right of the middle sequence, the rank sum for $S$. mansoni was numerically enlarged to 22 , and the rank sum of $A$. lumbricoides was reduced to 10 , thus suggesting a negative association between percentage of infections with $A$. lumbricoides and infections with S. mansoni.

For rearranged data from Chunge and co-works

${ }^{21}$, two communities in Kenya are compared according to age groups (Table 4). In the Miu community, in the first age group (0-5), for instance, the prevalence value in $A$. lumbricoides cases was 1.5 and 2.9 in schistosomiasis cases, while in the Kitinger community the prevalence of roundworm was reduced to 0.9 and the proportion of schistosomiasis was increased to 7.8, thus suggesting a negative association between percentage of infections with $A$. lumbricoides and infections with S. mansoni (concordant pair). Discordant pairs were seen only in the $11-15$ and $>50$ age groups. All together, concordant pairs are 5 out of $7(71.4 \%)$ age groups.

For rearranged data from Mamo and co-works ${ }^{23}$, again starting with the Ethiopian first age group (Table $5)$, the 0-4 age group showed a prevalence value for $A$. lumbricoides infection of $41.9 \%$ and for schistosomiasis $38 \%$. In the 5-9 age group where $A$. lumbricoides was increased to $56.6 \%$, the proportion of schistosomiasis was reduced to $0.31 \%$. When compared with their predecessor, this suggests a concordant pair, that is, a negative association between percentage of infections with $A$. lumbricoides and infections with $S$. mansoni. Discordant pairs were seen only in the 20-24 and 30-34 age groups, where the proportion of Ascaris was reduced when compared with their predecessor, but the 
Table 1- Changes in cytotoxic antibody ${ }^{b}$ titration by presence or absence of Ascaris before and ${ }^{3} 5$ months after treatment with anti-schistosomal and/or anti-geohelminth drugs.

\begin{tabular}{|c|c|c|c|c|c|c|c|c|c|c|c|}
\hline \multirow[t]{4}{*}{$\begin{array}{l}\text { A) Absence } \\
\text { of Ascuris }\end{array}$} & \multirow{4}{*}{$\begin{array}{l}\text { Parasitological status }{ }^{\circ} \\
\text { Treatment: } \\
\text { Before } \\
\text { After } 5 \text { months } \\
\text { Sign of difference } \\
\text { (after before) }\end{array}$} & \multirow{3}{*}{$\begin{array}{l}S \\
26.6 \\
2.8\end{array}$} & \multirow{3}{*}{$\begin{array}{l}\mathrm{S}+\mathrm{Hn} \\
74.0 \\
12.6\end{array}$} & \multicolumn{2}{|l|}{$\mathrm{S}$} & $\mathrm{S}$ & $S$ & $\mathrm{~s}$ & $\mathrm{~s}$ & \multicolumn{2}{|l|}{$\mathrm{GM}^{\mathrm{c}}$} \\
\hline & & & & \multicolumn{2}{|l|}{158.4} & 52.0 & 157.8 & 136.7 & 170.0 & \multicolumn{2}{|l|}{92.8} \\
\hline & & & & \multicolumn{2}{|c|}{85.848 .0} & 450.0 & 107.4 & 14.5 & 37.3 & & \\
\hline & & - & - & - & - & - & - & + & - & & \\
\hline $\begin{array}{l}\text { B) Presence } \\
\text { of Ascuris }\end{array}$ & $\begin{array}{l}\text { Parasitological status } \\
\text { Treatment: }\end{array}$ & $S+A$ & & $S+A+T+S s$ & $\mathrm{~S}$ & & $\mathrm{~A}+\mathrm{H}$ & $S+A$ & $S+A$ & $S+A$ & GM \\
\hline & Before & 49.1 & & 45.7 & & & 4.5 & 68.4 & 79.3 & 49.0 & 59.1 \\
\hline & After 5 months & 377.0 & & 48.0 & & & 5.2 & 85.8 & 85.2 & 15.0 & 76.1 \\
\hline & $\begin{array}{l}\text { Sign of difference } \\
\text { (after before) }\end{array}$ & + & & + & - & & + & + & + & - & + \\
\hline
\end{tabular}

Note a S: Schistosoma mansoni. Hn: Hymenolepis nana. A: Ascaris. T: Trichuris. Ss: Strongyloides stercoralis. H: hookworm. ${ }^{\mathrm{b}}$ Against S. mansoni schistosomula in vitro (14). Blood was collected from individuals prior to and ${ }^{3} 5$ months after the Oxamniquine (for $S$. mansoni) and/or Mebendazole (for intestinal helminths) treatments. ${ }^{c}$ Geometric mean.

Table 2- Alemayehu and colleagues ${ }^{18}$ Tigray region, Ethiopia data: Checking if the prevalence of Ascaris remained the same while the proportion of schistosomiasis as microdams progressed

\begin{tabular}{|c|c|c|c|c|c|c|c|c|c|c|c|c|c|c|}
\hline $\mathrm{Md}^{\mathrm{a}}$ & A & $\mathrm{F}$ & MA & AS & $A B$ & $\mathrm{AH}$ & MG & TA & G & C & MM & MAG & $\mathrm{R}$ & G \\
\hline $\mathrm{Sm}$ & 0 & 0 & 0 & 0 & 0 & 0 & 0 & 0 & 1 & 2 & 2 & 3 & 4 & 4 \\
\hline Asc & 2 & 2 & 2 & 4 & 4 & 5 & 5 & 31 & 0 & 0 & 0 & 3 & 0 & 2 \\
\hline
\end{tabular}

Microdams (first letters of name), S. mansoni or Ascaris, in prevalence by dam (total-28). Arithmetic mean of Ascaris infection for first half of the ordered sequence of $S$. mansoni values is 4.3 .

b) Second half of ordered sequence of prevalence ofSchistosoma mansoni ( $\mathrm{n}=14$ microdams)

\begin{tabular}{|c|c|c|c|c|c|c|c|c|c|c|c|c|c|}
\hline $\mathrm{Md}^{\mathrm{a}}$ & ASG & $M$ & $\mathrm{AW} / \mathrm{H}$ & $\mathrm{HW}$ & $\mathrm{MA}$ & $M D$ & MG & $\mathrm{MT}$ & $\mathrm{MA}$ & GC & MS & MS & GB \\
\hline $\mathrm{Sm}$ & 5 & 5 & 5 & 8 & 9 & 10 & 16 & 21 & 21 & 22 & 23 & 33 & 37 \\
\hline Asc & 0 & 0 & 2 & 0 & 9 & 2 & 4 & 0 & 0 & 2 & 3 & 2 & 5 \\
\hline
\end{tabular}

"Microdams (first letters of name), S. mansoni or Ascaris, in prevalence by dam (total=28). Arithmetic mean of Ascaris infection for second half of the ordered sequence of $S$. mansonivalues is 2.3 .

Table 3- Rearranged data from Fleming and colleagues $^{10}$ : according to prevalence of Ascaris infection target, prevalence of $S$. mansoni infections was assigned by ranks

\begin{tabular}{ccccccccccc}
\hline Age & $0-5$ & $5-10$ & $10-20$ & $10-20$ & $20-30^{c}$ & $30-40$ & $40-50$ & $50-60$ & 70 & 3 \\
$\mathrm{Sm}^{\mathrm{a}}$ & $1^{\mathrm{b}}$ & 2 & 8 & 5 & 7 & 6 & 9 & 4 & 3 \\
$\mathrm{Asc}$ & 7 & 9 & 8 & 6 & 5 & 2.5 & 2.5 & 1 & 4 \\
\hline
\end{tabular}

a Schistosoma mansoni or Ascaris. ${ }^{\mathrm{b}}$ Ranks. ${ }^{\mathrm{c}}$ Middle of ordered sequence of age group (age ranged 0-5 and was obtained by extrapolation). Rank sum for Ascaris infection at left of the middle sequence value is 30 and at right is lower or 10, and in the same order for S. mansoni infection it is 16 and 22. Total individuals=1332.

proportion of schistosomiasis was not increased. All together, concordant pairs are 10 out of 13 (or $76.9 \%$ ). Identical analysis was performed with Birrie and colleagues ${ }^{19}$ data with $75 \%$ concordant pairs (Table 6 ).

Finally, the prevalence, percentage of heavily infected or mean egg count from children categorized by $\operatorname{sex}^{20}$ are rearranged and summarized in Table 7 . For
S. mansoni data the percentages of infected, heavily infected and mean egg count were greater in males than females. Although we did not observe a clear-cut numerical difference in prevalence of ascariasis by sex (males=42.1; females=41.6), in schistosomiasis there was a consistent decrease in heavily infected and mean egg counts from males to females. 
Table 4 - Chunge and colleagues ${ }^{21}$ data: percentage of schistosomiasis cases compared to percentage of Ascaris infection by age group ( $0-5$ through $>50)$ in two Kenya communities.

\begin{tabular}{|c|c|c|c|c|c|c|c|c|c|c|c|c|c|c|}
\hline & \multicolumn{14}{|c|}{ Age } \\
\hline & \multicolumn{2}{|c|}{$0-5$} & \multicolumn{2}{|c|}{$6-10$} & \multicolumn{2}{|c|}{$11-15$} & \multicolumn{2}{|c|}{$16-20$} & \multicolumn{2}{|c|}{$21-30$} & \multicolumn{2}{|c|}{$31-50$} & \multicolumn{2}{|c|}{$>50$} \\
\hline & $\mathrm{Miu}^{\underline{b}}$ & $\mathrm{Kit}^{\mathrm{b}}$ & Miu & Kit & Miu & Kit & Miu & Kit & Miu & Kit & Miu & Kit & Miu & Kit \\
\hline $\mathrm{Sm}^{a}$ & 2.9 & 7.8 & 23.5 & 30 & 12.7 & 20.5 & 22 & 28.4 & 32.7 & 32.8 & 28.2 & 32.2 & 29.1 & 32 \\
\hline \multirow[t]{2}{*}{$\mathrm{Asc}^{\mathrm{a}}$} & 1.5 & 0.9 & 2.5 & 0 & 0 & 2.6 & 4 & 0 & 3.3 & 0 & 4.7 & 0 & 1.8 & 4 \\
\hline & \multicolumn{2}{|c|}{$C^{c}$} & \multicolumn{2}{|l|}{ C } & \multicolumn{2}{|c|}{$D$} & \multicolumn{2}{|l|}{ C } & \multicolumn{2}{|c|}{ C } & \multicolumn{2}{|c|}{ C } & \multicolumn{2}{|c|}{ D } \\
\hline
\end{tabular}

a Schistosoma mansoni and Ascaris. ${ }^{b}$ Miu and Kitinger communities. ${ }^{c}$ Concordant (C) or discordant (D) pairs (see text). Total individuals: Miu, 464; Kitinger, 547.

Table 5- Mamo, Assefa e Lo ${ }^{23}$ Ethiopia data: percentage of schistosomiasis cases compared to percentage of Ascaris cases according eleven age groups (0-4 through $>50)$.

\begin{tabular}{cccccccccccc}
\hline & & \multicolumn{10}{c}{ Age } \\
\hline \multirow{3}{*}{$\mathrm{Sm}^{\mathrm{a}}$} & $0-4$ & $5-9$ & $10-14$ & $15-19$ & $20-24$ & $25-29$ & $30-34$ & $35-39$ & $40-44$ & $45-49$ & $>50$ \\
$\mathrm{Asc}$ & 0.38 & 0.31 & 3.8 & 4.5 & 2.1 & 0.8 & 0.6 & 0 & 1.7 & 2.2 & 3.3 \\
& 41.9 & 56.6 & 45.3 & 31.5 & 26.1 & 28.3 & 27.7 & 28 & 19.3 & 36.3 & 30 \\
& & $\mathrm{c}^{\mathrm{b}}$ & $\mathrm{C}$ & $\mathrm{C}$ & $\mathrm{D}$ & $\mathrm{C}$ & $\mathrm{D}$ & $\mathrm{C}$ & $\mathrm{C}$ & $\mathrm{D}$ & $\mathrm{C}$ \\
\hline
\end{tabular}

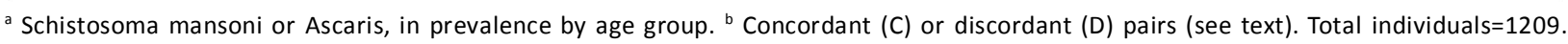

Table 6- Birrie, Erko e Tedla ${ }^{19}$ Ethiopia data: percentage of schistosomiasis cases compared to percentage of Ascaris cases according to 13 age groups (0-4 through $>60)$.

\begin{tabular}{cccccccccccccc}
\hline \multicolumn{10}{c}{ Age } \\
\hline \multirow{3}{*}{$\mathrm{Sm}^{\text {a }}$} & $0-4$ & $5-9$ & $10-14$ & $15-19$ & $20-24$ & $25-29$ & $30-34$ & $35-39$ & $40-44$ & $45-49$ & $50-54$ & $55-59$ & $>60$ \\
$\mathrm{Asc}$ & 0,8 & 8.1 & 10.3 & 10 & 4.6 & 6 & 5.9 & 13.8 & 26.5 & 18.5 & 7.6 & 9 & 29.4 \\
& 20,1 & 18.3 & 12.4 & 1.6 & 4.6 & 0 & 1.4 & 0 & 0 & 0 & 3.8 & 0 & 5.8 \\
& & $C^{b}$ & $C$ & $D$ & $C$ & $C$ & $C$ & $C$ & $C$ & $D$ & $C$ & $C$ & $D$ \\
\hline
\end{tabular}

${ }^{a}$ Schistosoma mansoni or Ascaris, in prevalence by age group. ${ }^{b}$ Concordant (C) or discordant (D) pairs (see text). Total individuals=1537.

Table 7- Brooker and colleagues ${ }^{20}$ children (Busia District, Kenya) data: Rearrangement of data for the prevalence and mean egg counts of schistosomiasis mansoni and ascariasis by sex.

\begin{tabular}{lcccccccc}
\hline & \multicolumn{2}{c}{ \%of infected } & & \multicolumn{2}{c}{ \% heavily infection } & & \multicolumn{2}{c}{ Mean egg count } \\
\cline { 2 - 3 } \cline { 8 - 10 } S.Manson & Males & Females & & Males & Females & & Males & Females \\
Ascaris & 24.5 & 18.7 & & 5.7 & 3.0 & & 108 & 66 \\
& 42.1 & 41.6 & & 4.0 & 5.2 & 2247 & 2410 \\
\hline
\end{tabular}

Total individuals: males=943; females $=795$.

\section{DISCUSSION}

The main purpose of this study was to investigate a possible interference between $S$. mansoni and $A$. lumbricoides infections. The occurrence of Ascaris and $S$. mansoni interaction is very remarkable, because this blood fluke and roundworm do not have the same habitat and biotic environmental requirements. In addition, Ascaris is independent of water sources for transmission while water contact is one of the most important epidemiological factors in Schistosoma infection. However, both juvenile-stage worms undergo a tissuemigratory phase involving the liver and lungs and show distinct mechanisms that induce an inflammatory reaction into the host.

We present evidence that Ascaris infections influence the levels of complement-dependent antibody killing of schistosomula, inducible in human schistosomiasis over two follow-up periods. Thus, the effect of drug administration on antibody cytotoxicity is confounded by the presence of $A$. lumbricoides, and this may be important because $S$. mansoni schistosomula are the first stage in vivo, and therefore, they are an important target for immunological control in which 
complement and antibodies act synergistically in killing these larvae. At least in part, this result is supported by the finding that the eosinophil-dependent cytotoxicity against schistosomula was enhanced after treatment in some individuals ${ }^{24}$ and that in praziquantel-treated chronic schistosomotic individuals the complementactivating antibody response to larval antigens was high by three months after treatment ${ }^{25}$. The participation of products released from $S$. mansoni in infected humans has been reported using antibody to kill schistosomula in the presence of eosinophils and complement ${ }^{26}$.

Altogether, the gain in cytotoxic antibody activity is intriguing and suggestive of a potential interference of $A$. lumbricoides infection. However, the co-infected individuals could differ from those infected with $S$. mansoni alone in other ways that might influence immune response (age, sex, host behaviour, parasite acquisition, etc) ${ }^{27,28}$. Although the sample size is small to make definitive conclusion regarding immunological processes and the characterization of the subjects should be ameliorated to be used in-vitro killing assay, this present observation also might contribute to the combination of laboratory studies with epidemiologic studies.

In fact, an inverse association between S. mansoni infection and $A$. lumbricoides infection was observed, since the prevalence of schistosomiasis tends to decrease with an increased prevalence of ascariasis. So in this study whose approaches range so widely, is necessary an attempt to convince by the weight and variety of evidence because the observed differences might be due to some confounding effect and not host parasite interaction.

Note that in this preliminary communication an analysis based on statistical significance tests was not presented. Even if a test is not significant, the result could be important for health purposes ${ }^{29}$. It is important to concentrate on epidemiological concepts because they may have a public health impact instead focusing only on the mean prevalence not being different between groups. Indeed, in the present study, we are not just interested in determining if significant difference between the mean prevalences occurred. Therefore, we believe that the present results could be helpful. Given that the present data were obtained from surveys in some "hidden" published data, the findings need to be confirmed by a well-designed randomised controlled trial before definite conclusions can be made about the effects of $A$. lumbricoides in the environment on the prevalence of $S$. mansoni. The prevalence of schistosomiasis might be confounded by the presence of $A$. lumbricoides, and this raises the possibility that one species may influence the transmission patterns or disease features caused by another ${ }^{4}$.

Factors accounting for the present observations are unknown. Present findings are in agreement with the hypothesis of negative association between the prevalence of S. mansoni and A. lumbricoides. Besides, it is possible that suitable conditions for transmission of both parasites do not exist in all communities since biogeographical areas varied considerably ${ }^{11,30}$.

In conclusion, investigating the association between S. mansoni and $A$. lumbricoides and relating them with complement-activating antibodies and with prevalence of infectious agents could be essential in the understanding of parasite infections and in the formulation of epidemiological models that can maximize the efficacy of control measures.

\section{Acknowledgments}

To Dr. Francisco Juarez Ramalho-Pinto for preliminary reading and suggestions

\section{REFERENCES}

1. BRITO, L. L. et al. Moderate and low-intensity co-infections by intestinal helminths and Schistosoma mansoni, dietary iron intake, and anemia in Brazilian children. Am. J. Trop. Med. Hyg., Baltimore, v. 75, n. 5, p. 939-944, 2006.

2. CHAMONE, M.; ATUNCAR, G. S.; COELHO, P. M. Z.

Thermostability of heterophile antibodies from human sera infected with Schistosoma mansoni and geo-helminths. An immuno-metric statistical analysis. R. Inst. Med. Trop. São Paulo, São Paulo, v. 48, n. 3, p.157-165, May./June. 2006.

3. CHAMONE, M., MARQUES, C. A.; ALVES-OLIVEIRA, L. Does ancylostomiasis favour the intensity of Schistosoma mansoni infection? Trans. R. Soc. Trop. Med. Hyg., London, v. 80, n. 6, p. 1005, 1986.

4. CHAMONE, M. et al. Are there interactions between schistosomes and intestinal nematodes? Trans. R. Soc. Trop. Med. Hyg., London, v. 84, n. 4, p. 557-558, July. 1990.

5. PULLAN, R. L. et al. Human helminth co-infection: analysis of spatial patterns and risk factors in a Brazilian community. Plos. Negl. Trop. Dis., San Francisco, v. 2, n. 12, p. 352, Dec. 2008.

6. SILVA, R. C. R. et al. The relative influence of polyparasitism, environment, and host factors on schistosome infection. Am. J. Trop. Med. Hyg., Baltimore, v. 77, n. 4, p. 672-675, 2007.

7. ALVES-OLIVEIRA, L. et al. Quantitative complement fixation test in sera from patients with schistosomiasis and intestinal parasites. Ann. Trop. Med. Parasitol., Liverpool, v. 77, n. 5, p. 541-542, 1983.

8. ZWINGENBERGER, A. H. et al. Impaired balance of interleukin4 and interferon-y production in infections with Schistosoma mansoni and intestinal nematodes. Scand. J. Immunol., Oslo, v. 34, n. 2, p. 243-251, Aug. 1991.

9. WEBSTER, M. et al. Factors affecting high and low human IgE responses to schistosome worm antigens in an area of Brazil endemic for Schistosoma mansoni and hookworm. Am. J. Trop. Med. Hyg., Baltimore, v. 57, n. 4, p. 487-494, Oct. 1997.

10. FLEMING, F. M. et al. Synergistic associations between hookworm and other helminth species in a rural community in Brazil. Trop. Med. Int. Health., Oxford, v. 11, n. 1, p. 56-64, Jan. 2006.

11. KEISER, J. et al. Association between Schistosoma mansoni and hookworm infections among schoolchildren in Cote d'Ivoire. Acta Trop., Basel, v. 84, n. 1, p. 31-41, Oct. 2002.

12. RASO, G. et al. Multiple parasite infections and their relationship to self-reported morbidity in a community of rural Côte d'Ivoire. Int. J. Epidemiol., London, v. 33, n. 5, p. 10921102, 2004. 
13. CORREA-OLIVEIRA, R. et al. Human antibody responses against schistosomnal antigens. I- Antibodies from patients with Ancyslostoma, Ascaris lumbricoides or Schistosoma mansoni infections react with schistosome antigens. Am. J. Trop. Med. Hyg., Baltimore, v. 38, n. 2, p. 348-355, 1988.

14., KAGAN, I. G.; PELLEGRINO, J. A critical review of immunological methods for the diagnosis of bilharziasis. Bull. World Health Organ., Geneve, v, 25, n. 4/5, p. 611-674, 1961.

15. LURIE, H. I. ; DE MEILLON, B. Skin tests for schistosomiasis. S. Afr. Med. J., Cape Town, v. 25, n. 19, p. 321-324, 1951.

16. CHAMONE, M. et al. Characterization of human heterophile hemolysins induced by Schistosoma mansoni infection. Mem. Inst. Oswaldo Cruz., Rio de Janeiro, v. 78, n. 3, p. 257-267, July/ Sept. 1983.

17. ERICHSEN, E. S. Níveis de anticorpo letal antes e após quimioterapia específica em pacientes com esquistosomose mansoni. 1992. 100 f. Dissertação (Mestrado em Microbiologia) - Universidade Federal de Minas Gerais, Belo Horizonte, 1992.

18. ALEMAYEHU, T. et al. Malaria, shistosomiasis and intestinal helminths in relation to microdams in Tigray, Northern Ethiopia. Parassitologia, Roma, v. 40, n. 3, p. 259-267, Sept. 1998.

19. BIRRIE, H.; ERKO, B.; TEDLA, S. Intestinal helminthic infections in the southern Rift Valley of Ethiopia with special reference to schistosomiasis. East. Afr. Med. J., Nairobi, v. 71, n. 7, p. 447-52, July. 1994

20. BROOKER, S. et al. Epidemiology of single and multiple species oh helminth infections among school children in Busia Distric, Kenya. East. Afr. Med. J., Nairobi, v. 77,

n. 3, p. 157-161, 2000

21. CHUNGE, R. N. et al. Polyparasitism in two rural communities with endemic Schistosoma mansoni infection in Machakos District. J. Trop. Med. Hyn., London, v. 98, n. 6, p. 440-444, Dec. 1995.
22. HIATT, R. A. Morbidity from Schistosoma mansoni infections and epidemiologic study based on quantitative analysis of egg excretion in two highland Ethiopian villages. Am. J. Trop. Med. Hyg., Baltimore, v. 25, n. 6, p. 808-817, Nov. 1976.

23. MAMO, B.; ASSEFA, B.; LO, C. T. Intestinal helminths in Akakintown with special emphasis on the epidemiology of Schistosoma mansoni. Ethiop. Med. J., Addis Abada, v. 27, n.4 , p.183-191, 1989.

24. KIMANI, G. et al. Immune responses after treatment for Schistosoma mansoni infections. Scand. J. Immunol., Oslo, v. 11, p. 29-33, 1992. Suppl.

25. JASSIM, A.; HASSAN, K.; CATTY, D. Antibody isotypes in human schistosomiasis mansoni. Parasite Immunol., Oxford, v. 9, n. 6, 627-650, Nov. 1987

26. VERWAERDE, C. et al. IgG response of rats and humans to the released products of schistosomula of Schistosoma mansoni. Parasitology, London, v. 90, pt. 3, p. 509-518, June. 1985.

27. COOPER, P. J. et al. Human infection with Ascaris lumbricoides is associated with suppression of the interleukin2 response to recombinant Cholera toxin $\mathrm{B}$ subunit following vaccination with the live oral Cholera vaccine CVD 103-HgR. Infect. Immun., Washington,

v. 69, n. 3, p. 1574-1580, Mar. 2001.

28. SOUZA, J. R. et al. Treatment of human acute schistosomiasis with oxamniquine induces an increase in interferon-ã response to Schistosoma mansoni antigens. Mem. Inst. Oswaldo Cruz., Rio de Janeiro, v. 102, n. 2, p. 225-228, Mar. 2007.

29. STELZL, I. What sample sizes are needed to get correct significance levels for log-linear models? - A Monte Carlo Study using SPSS-procedure "Hiloglinear". Meth. Psychol. Res. Online, v. 5, n. 2. p. 95-116, 2000.

30. DE CLERCQ, D. et al. . - Schistosoma and geohelminth infections in Mali, west Africa. Ann. Soc. Belg. Med. Trop., Bruxelles, v. 75, n. 3, p. 191-199, Sept. 1995. 